Article

\title{
Induction of PLXNA4 Gene during Neural Differentiation in Human Umbilical-Cord-Derived Mesenchymal Stem Cells by Low-Intensity Sub-Sonic Vibration
}

\author{
Hyunjin Cho ${ }^{1}$, Hee-Jung Park ${ }^{2}$ and Young-Kwon Seo ${ }^{2, *} \mathbb{D}$ \\ 1 Research Institute of Integrative Life Sciences, Dongguk University, Goyang-si 10326, Korea; \\ dr.hjcho@hanmail.net \\ 2 Department of Medical Biotechnology (BK21 Plus Team), Dongguk University, Goyang-si 10326, Korea; \\ gnflwldk98@naver.com \\ * Correspondence: bioseo@dongguk.edu
}

check for updates

Citation: Cho, H.; Park, H.-J.; Seo, Y.-K. Induction of PLXNA4 Gene during Neural Differentiation in Human Umbilical-Cord-Derived Mesenchymal Stem Cells by Low-Intensity Sub-Sonic Vibration. Int. J. Mol. Sci. 2022, 23, 1522. https: / /doi.org/10.3390/ijms 23031522

Academic Editor: Jan Kaslin

Received: 24 December 2021

Accepted: 27 January 2022

Published: 28 January 2022

Publisher's Note: MDPI stays neutral with regard to jurisdictional claims in published maps and institutional affiliations.

Copyright: (C) 2022 by the authors. Licensee MDPI, Basel, Switzerland. This article is an open access article distributed under the terms and conditions of the Creative Commons Attribution (CC BY) license (https:// creativecommons.org/licenses/by/ $4.0 /)$.

\begin{abstract}
Human umbilical-cord-derived mesenchymal stem cells (hUC-MSC) are a type of mesenchymal stem cells and are more primitive than other MSCs. In this study, we identify novel genes and signal-activating proteins involved in the neural differentiation of hUC-MSCs induced by Low-Intensity Sub-Sonic Vibration (LISSV). RNA sequencing was used to find genes involved in the differentiation process by LISSV. The changes in hUC-MSCs caused by LISSV were confirmed by PLXNA4 overexpression and gene knockdown through small interfering RNA experiments. The six genes were increased among genes related to neurons and the nervous system. One of them, the PLXNA4 gene, is known to play a role as a guide for axons in the development of the nervous system. When the PLXNA4 recombinant protein was added, neuron-related genes were increased. In the PLXNA4 gene knockdown experiment, the expression of neuron-related genes was not changed by LISSV exposure. The PLXNA4 gene is activated by sema family ligands. The expression of SEMA3A was increased by LISSV, and its downstream signaling molecule, FYN, was also activated. We suggest that the PLXNA4 gene plays an important role in hUC-MSC neuronal differentiation through exposure to LISSV. The differentiation process depends on SEMA3A-PLXNA4-dependent FYN activation in hUC-MSCs.
\end{abstract}

Keywords: hUC-MSCs; low-intensity sub-sonic vibration; PLXNA4; SEMA3A; neural signaling

\section{Introduction}

The conversion of mechanical stimuli into biochemical information within cells provides biological activation or inactivation signals in various cell types. Mechanical stimulation is a kind of physical force and has various effects on cells through the regulation of cell proliferation and differentiation. Among categories of cells, mesenchymal stem cells (MSCs) are differentiated into various types and have great potential for tissue engineering.

Although many studies on mechanical stimuli have been reported, few have examined the effect on MSCs. In vascular tissue engineering studies, bone marrow-derived MSCs (BM-MSCs) were differentiated into endothelial-like cells by shear stress [1-3], and these results were similar to other tissue-derived MSCs, such as human placenta and adiposederived MSCs [4]. In cartilage tissue engineering, the combined treatment of MSCs with chondrocytes improves symptoms of knee cartilage defects [5], and Lin et al. reported a synergistic effect of cartilage regeneration by dynamic compression in BM-MSCs [6]. Most of the studies were performed by adding enzymes, cytokines, and growth factors that support the potential regenerative capacity of MSCs, in addition to mechanical stimulation [4-7].

Sub-sonic refers to a frequency that is so low that it is inaudible and slower than the speed of sound. Low-intensity vibration (LIV) is a stimulus that transmits vibration with intensity in the range of 20 to $200 \mathrm{~Hz}$ frequencies. LIV can be effective in improving the bone 
and muscle index at the tissue level [8-10] and reducing myeloma cell-induced osteoclast formation [11]. Furthermore, LIV decreased the pro-inflammatory cytokines IL-6, IFN- $\gamma$, and TNF- $\alpha$ in cultured murine macrophages [12] and inhibited tumor progression [13].

Plexin-A4 (encoded by PLXNA4) belongs to the plexin A family. It binds neuropilin to propagate signals with class 3 semaphorins (SEMA3) into neurons and plays an important role in the induction of axons to their synaptic target during neural development [14-17]. This complex activates the cdk-5-mediated isoform A of phosphatidylinositol 3-kinase enhancer and promotes glioma cell invasion through the modulation of Akt activity $[18,19]$. In a recent report, Plxna4 variants were found to be involved in Alzheimer's disease pathogenesis through amyloid beta deposition [20].

Several studies have examined the effects of mechanical stimulation alone on hMSCs and other cells. Previous work by our group and others reported the effects of mechanical stimulation in hMSCs [21-24]. Neural differentiation of hMSCs was induced by sonic vibration or/and electromagnetic fields, allowing therapeutic applications in models of spinal cord injury and ischemic stroke $[25,26]$. This mechanical stimulation equally induced neural differentiation of hMSCs, and in particular, morphological changes similar to the neural cell shape were dramatically induced by sub-sonic vibrations [21]. In the present study, we aimed to investigate key genes involved in this differentiation by low-intensity sub-sonic vibration (LISSV) through RNA sequencing based on next-generation sequencing.

\section{Results}

\subsection{RNA Sequencing Confirmed That Six Genes Were Increased by LISSV}

In a previous study, we reported the effect of LISSV on hUC-MSCs [21]. A morphological change in the cells was induced and the shape was close to that of neurons. To identify novel genes involved in this change, RNA-sequencing analysis was performed. In the gene expression analysis related to the cell differentiation of hUC-MSCs, 16 genes increased more than threefold, and among them, 5 genes increased during LISSV, including PLXNA4, FMN1, AREG, STMN2, and SERPINI1 (Figure 1). Protein levels were detected in a time-dependent manner. The levels of PLXNA4 increased, but FMN1 decreased, and levels of SERPINI1 were unchanged (Figure 2).

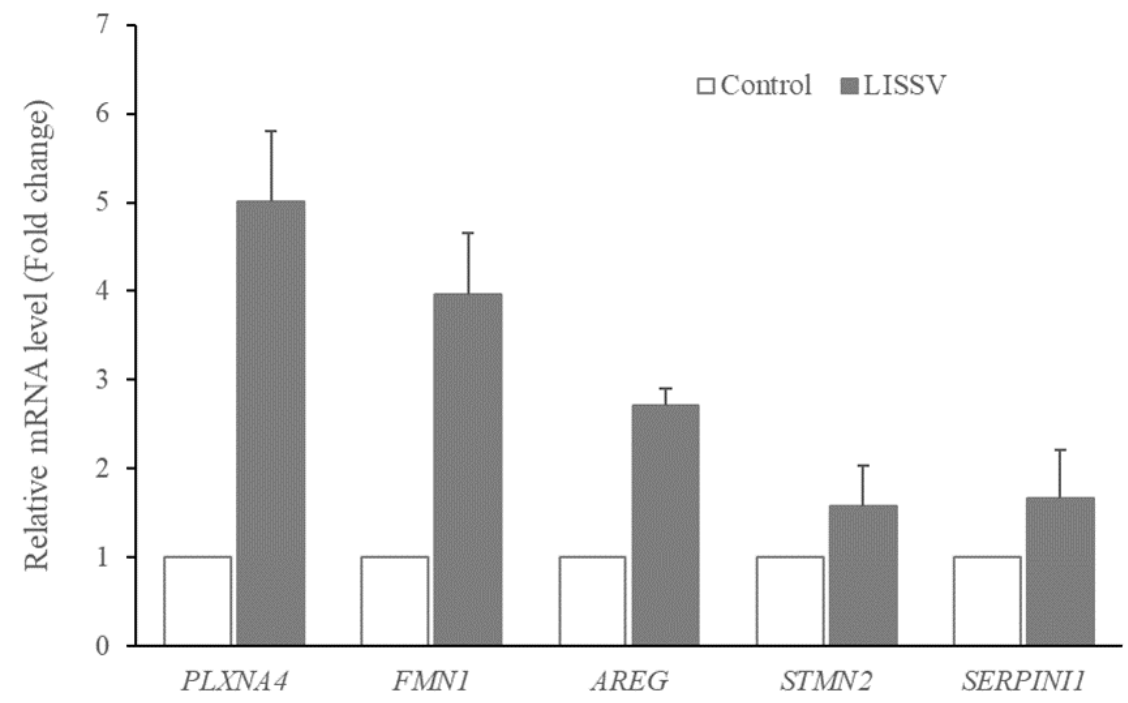

Figure 1. Expression of genes in human umbilical-cord-derived mesenchymal stem cells after lowintensity sub-sonic vibration treatment using RNA sequencing. Cells were harvested 4 days after LISSV treatment. Fold change in expression of Plexin-A4 (PLXNA4), Formin 1 (FMN1), Amphiregulin (AREG), Stathmin 2 (STMN2), and Serpin Family I Member 1 (SERPINI1). Assayed using real-time polymerase chain reaction. Column heights correspond to mean values and error bars to standard deviations $(n=3)$. 


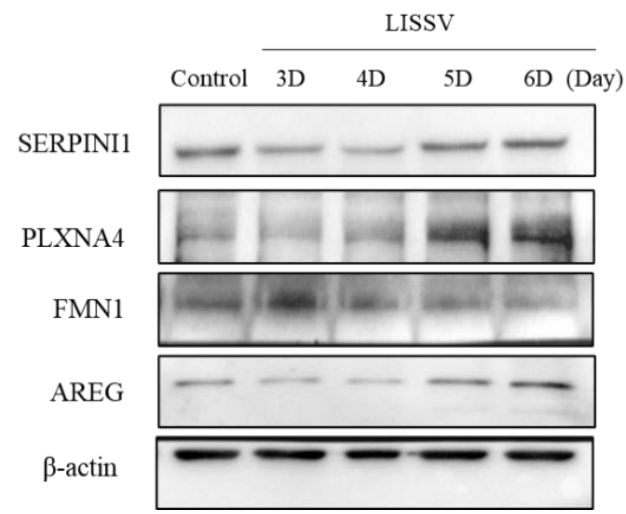

(a)

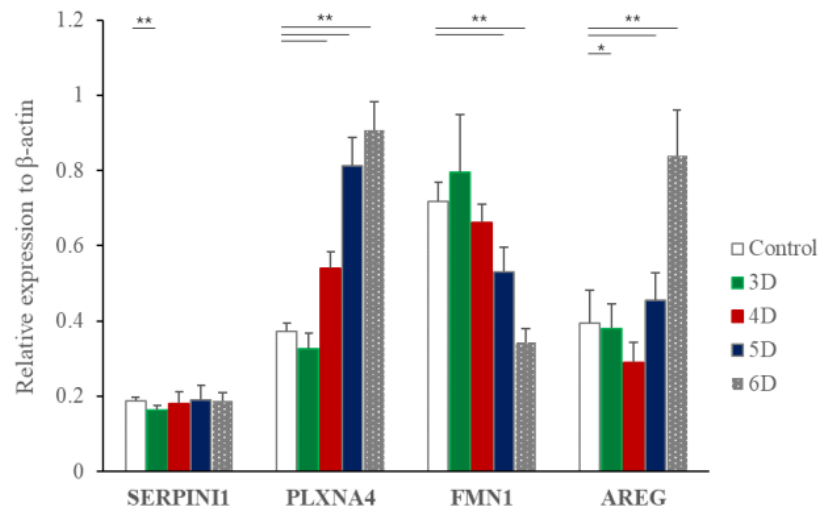

(b)

Figure 2. Expression of each protein in human umbilical-cord-derived mesenchymal stem cells after low-intensity sub-sonic vibration treatment. Proteins detected were Serpin Family I Member 1 (SERPINI1), Plexin A4 (PLXNA4), Formin 1 (FMN1), and Amphiregulin (AREG). (a) Western blot image. (b) Intensities of each Western blot band were quantified by Image J. Each band was normalized using $\beta$-actin. Column heights correspond to mean values and error bars to standard deviations $(n=3){ }^{*} p<0.05,{ }^{* *} p<0.01$.

\subsection{Recombinant PLXNA4 Protein Affected Neural Differentiation of hUC-MSCs}

Plexins are proteins involved in axon growth and are expressed on the surface of axon growth cones. Nine genes have been identified. PLXNA4 belongs to class A along with PLXNA1, PLXNA2, and PLXNA3. Plexin activation in growth cones causes actin and microtubule destabilization and endocytosis, involved in the contraction of growth cone protrusions [27]. The recombinant PLXNA4 protein was used for PLXNA4 overexpression analysis. The recombinant PLXNA4 protein was non-toxic in hUC-MSCs up to $2 \mu \mathrm{g} / \mathrm{mL}$ and significantly reduced the number of viable cells to $77 \%$ at $3 \mu \mathrm{g} / \mathrm{mL}$ (data were not shown). To demonstrate the effect on hUC-MSCs, the morphological changes in hUC-MSCs were observed daily after the addition of the recombinant PLXNA4 protein. Figure 3a shows that the amount of PLXNA4 gene expression increased after treatment with recombinant PLXNA4. On the fourth day, the inhibition of cell proliferation was confirmed by MTT assay (Figure $3 b$ ), and a morphological change was observed on the fifth day (Figure 4). The cells did not proliferate when treated with the recombinant PLXNA4 protein compared to controls, as they did with LISSV exposure. The cell body was brighter than that of the control group, and the filamentous shape was similar to that of the neuron. The expression of neuron-related genes by the PLXNA4 protein addition was confirmed, and the expression of most neuron-related genes, such as MAP2, NEUROD1, and NF-L, was increased, but for $M B P$ it was unclear (Figure 5). Voltage-gated calcium $\left(\mathrm{Ca}^{2+}\right)$ channels are key channels that induce changes in the membrane potential, and intracellular $\mathrm{Ca}^{2+}$ transients signal the initiation of many physiological events. The Cav2 subfamily is primarily responsible for the initiation of synaptic transmission [28]. The recombinant PLXNA4 protein has induced the expression of Cav2.1 and Cav2.2 genes in hUC-MSCs (Figure 6).

\subsection{The Neural Differentiation of hUC-MSCs by LISSV Was Not Induced upon PLXNA4 Gene Silencing}

siRNA is a gene-silencing assay in which the RNA-induced silencing complex binds to the target mRNA and interferes with the synthesis of the target protein. To evaluate the role of PLXNA4 in neuronal differentiation, we performed a silencing PLXNA4 expression experiment. We tested the cytotoxicity of siRNA duplex transfection in hUC-MSCs before siRNA experiments. When treated with $90 \mathrm{nmol}$ of siPLXNA4 duplex transfection, viable cells were $93.1 \%$ after siNegative control transfection and $90.4 \%$ after siPLXNA4 transfection (Figure 7). Figure 8 shows a morphological change or PLXNA4 level change in the case of silencing Negative (siNegative) control and PLXNA4 (siPLXNA4) expressions, which 
occurred with or without LISSV exposure. A universal, scrambled, negative control siRNA duplex was used as the silencing Negative (siNegative) control. This duplex and the transfection regents did not affect cells when exposed to LISSV compared to controls. The silencing Negative (siNegative) group with LISSV expressed the same level of PLXNA4 as the only LISSV-treated group, whereas the silencing Negative (siNegative) and PLXNA4 (siPLXNA4) groups with (+) or without (-) LISSV expressed no PLXNA4. The PLXNA4 gene was not expressed even in the silencing PLXNA4 (siPLXNA4) expression group with LISSV. LISSV exposure increased PLXNA4 levels in the silencing Negative (siNegative) control group but not in the silencing PLXNA4 (siPLXNA4) group. LISSV affects PLXNA4 gene expression, and PLXNA4 gene expression is thought to be associated with neural differentiation in hUC-MSCs. The expression of neuron-associated genes was analyzed by RT-qPCR in a PLXNA4 gene-silencing study. When the PLXNA4 gene was knocked down in hUC-MSC, the expression of neuronal-related genes, such as NF-L, MBP, and MAP2 genes, was not increased by LISSV (Figure 9).

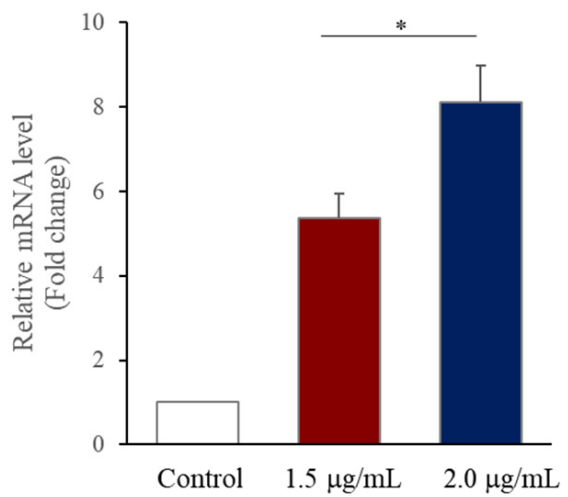

(a)

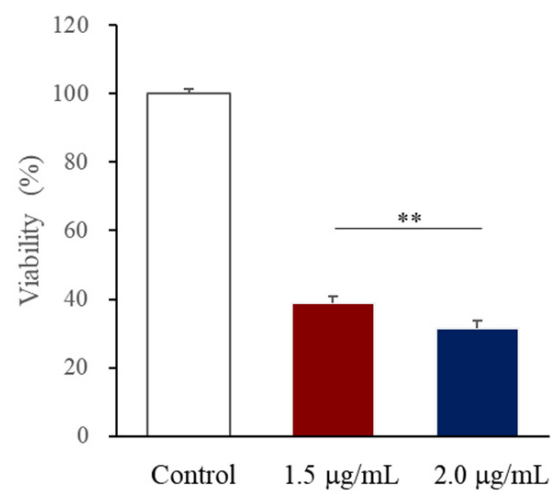

(b)

Figure 3. PLXNA4 gene expression after recombinant PLXNA4 protein treatment in human umbilicalcord-derived mesenchymal stem cells. Cells were harvested 4 days after recombinant PLXNA4 protein treatment. (a) Real-time PCR data of each protein. (b) MTT data show the inhibition of proliferation. Column heights correspond to mean values and error bars to standard deviations $(n=3) .{ }^{*} p<0.05, * * p<0.01$.
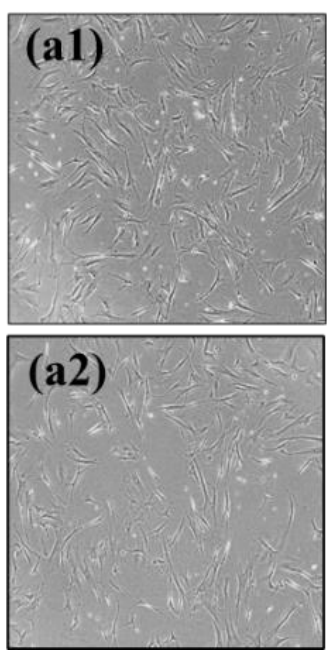
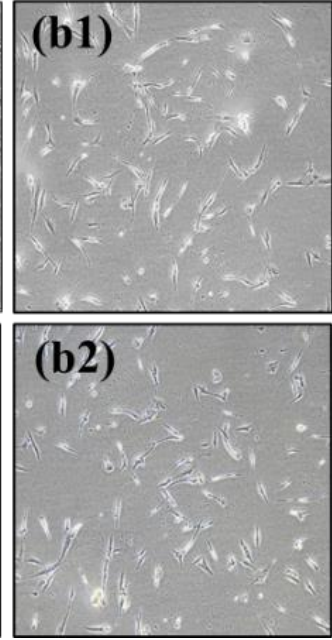
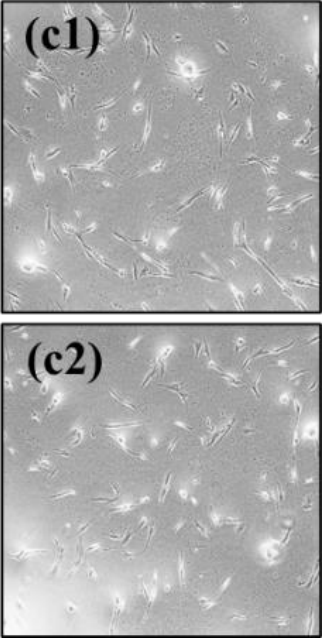

Figure 4. Morphological changes after recombinant PLXNA4 protein treatment for 5 days in human umbilical-cord-derived mesenchymal stem cells. (a1,a2): Untreated control cells. (b1,b2): $1.5 \mu \mathrm{g}$ of protein-treated cells. (c1,c2): $2.0 \mu \mathrm{g}$ of protein-treated cells. Original magnification $40 \times$. 


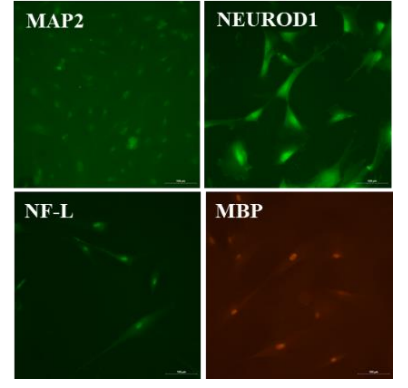

(a)

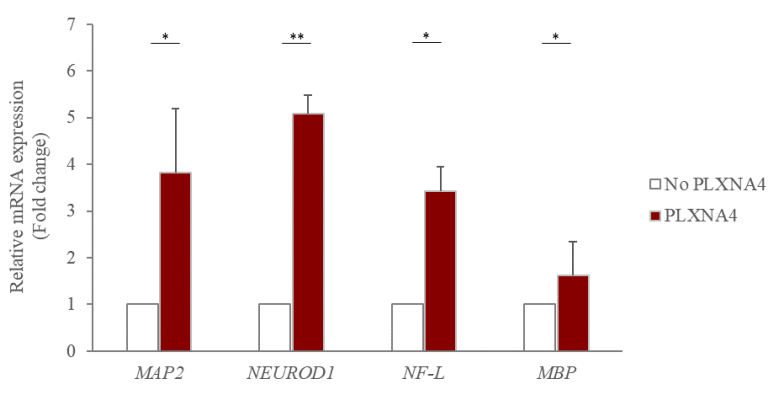

(b)

Figure 5. Expression of neuron-related proteins and genes in human umbilical-cord-derived mesenchymal stem cells after recombinant PLXNA4 protein treatment. Cells were harvested 5 days after $2 \mu \mathrm{g} / \mathrm{mL}$ recombinant PLXNA4 protein treatment. (a) Fluorescence images of each protein. Original magnification $200 \times$. (b) Fold expression of each gene using real-time polymerase chain reaction analysis. MAP2: Microtubule-associated protein 2. NEUROD1: Neuronal Differentiation 1, NF-L: Neurofilament-L, MBP: Myelin basic protein, Column heights correspond to mean values and error bars to standard deviations $(n=3) .{ }^{*} p<0.05,{ }^{* *} p<0.01$.

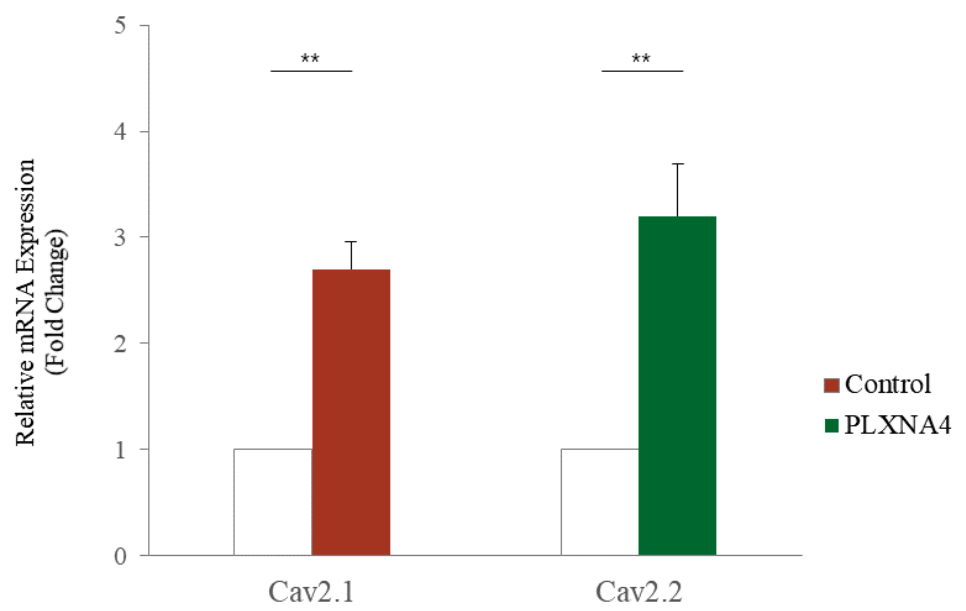

Figure 6. Expression of calcium channels in human umbilical-cord-derived mesenchymal stem cells after recombinant PLXNA4 protein treatment. Cells were harvested 5 days after $2 \mu \mathrm{g} / \mathrm{mL}$ recombinant PLXNA4 protein treatment. Fold expression of each gene using real-time polymerase chain reaction analysis. Cav2.1: Voltage-gated P/Q type calcium channel. Cav2.2: Voltage-gated $\mathrm{N}$-type calcium channel, Column heights correspond to mean values and error bars to standard deviations $(n=3)$. ${ }^{* *} p<0.01$.

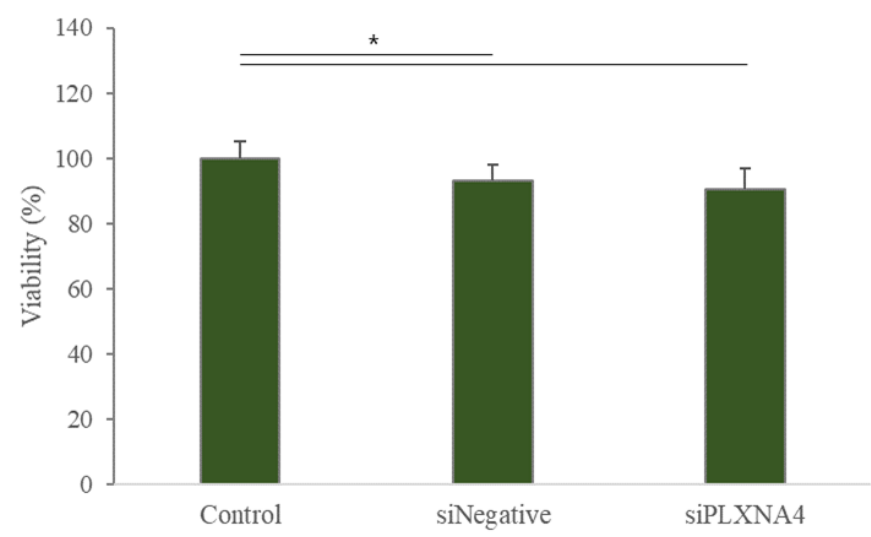

Figure 7. MTT data for siRNA transfection in human umbilical-cord-derived mesenchymal stem cells. Cells were harvested 2 days after siRNA duplex transfection. Column heights correspond to mean values and error bars to standard deviations $(n=3) .{ }^{*} p<0.05$. 


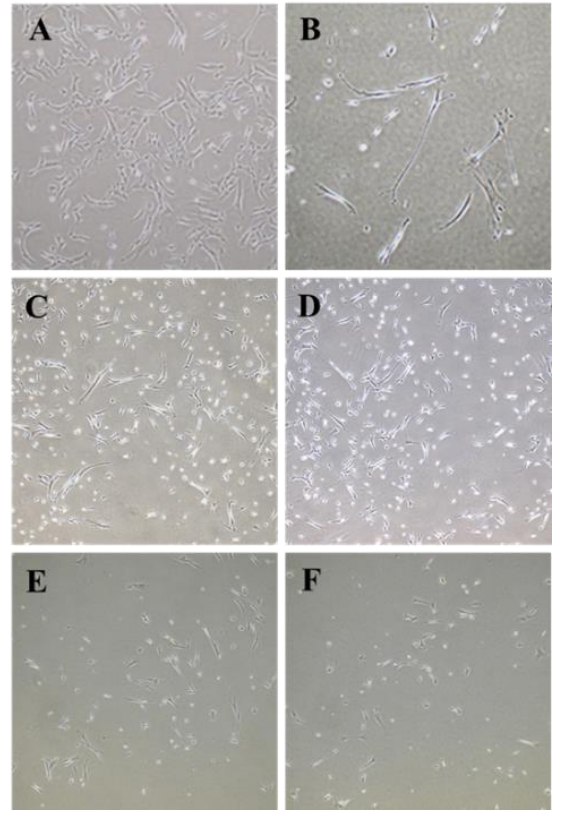

(a)

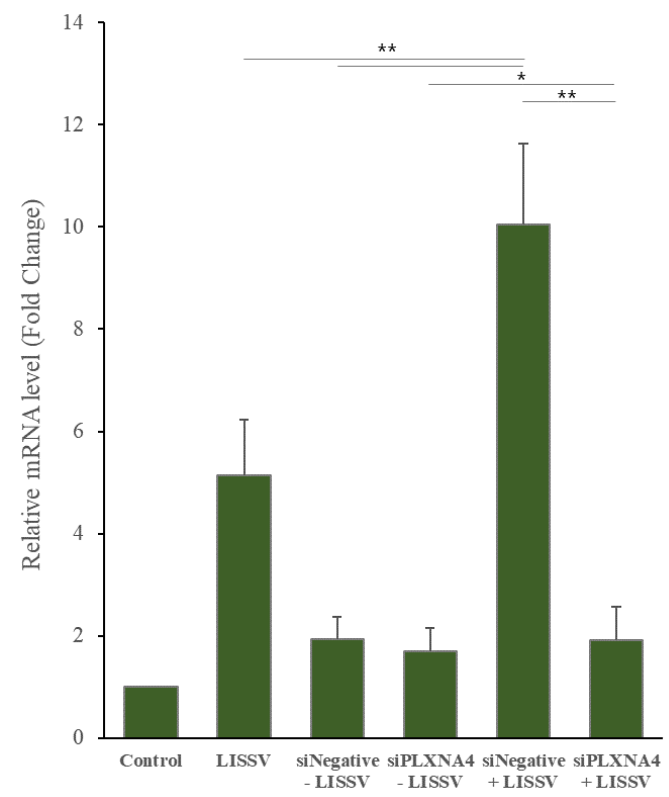

(b)

Figure 8. PLXNA4 gene silencing using small interfering RNA transfection methods in human umbilical-cord-derived mesenchymal stem cells. Cells were harvested 4 days after low-intensity sub-sonic vibration treatment. (a) Morphology of each sample: A. Control; B. low-intensity subsonic vibration (LISSV); C. siNegative duplex $90 \mathrm{nmol}$ without (-) LISSV; D. siPLXNA4 duplex 90 nmol without (-) LISSV; E. siNegative duplex with (+) LISSV; F. siPLXNA4 duplex with (+) LISSV. Original magnification $40 \times$. (b) Fold change in the expression PLXNA4 determined using real-time polymerase chain reaction analysis. Column heights correspond to mean values and error bars to standard deviations $(n=3) .{ }^{*} p<0.05,{ }^{* *} p<0.01$.
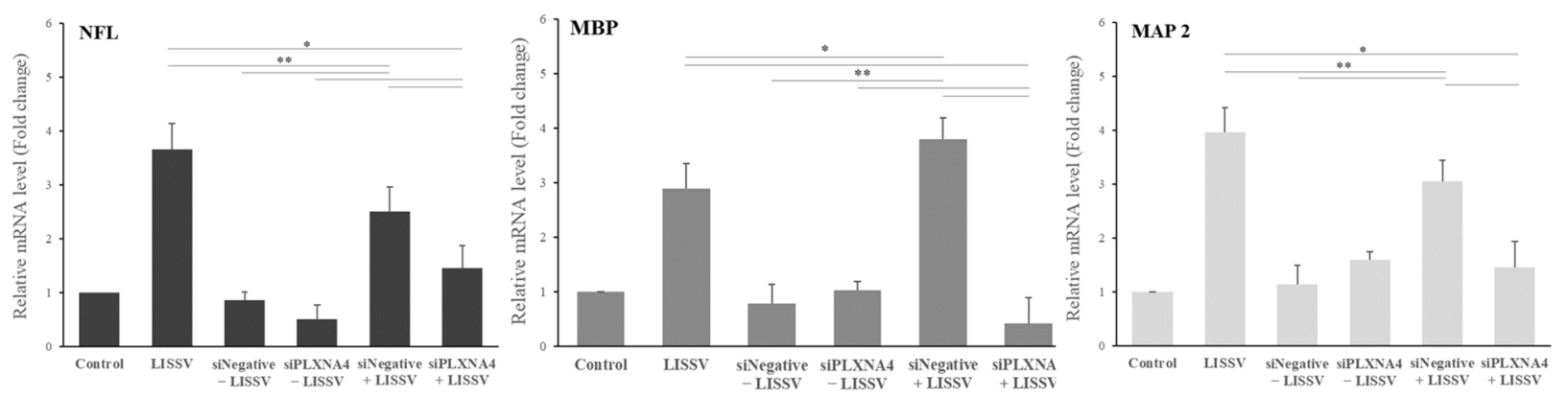

Figure 9. Expression of neuron-associated genes in human umbilical-cord-derived mesenchymal stem cells after siPLXNA4 duplex transfection using real-time polymerase chain reaction analysis. Cells were harvested 4 days after low-intensity sub-sonic vibration treatment. NF-L: Neurofilament-L, MBP: Myelin basic protein, MAP2: Microtubule-associated protein 2. Column heights correspond to mean values and error bars to standard deviations $(n=3)$. ${ }^{*} p<0.05,{ }^{* *} p<0.01$.

\subsection{Changes with LISSV versus PLXNA4 in Sema-Dependent Signaling}

Our results showed that the PLXNA4 gene is associated with neuronal differentiation of hUC-MSCs. In a previous study, we reported the differentiation of hUC-MSCs by LISSV [21]. The differentiation was induced in the LDMEM medium without any supplements for neural induction. The differentiation was non-specific, so genes related to oligodendrocytes, astrocytes, and neurons were all expressed. To compare neural differentiation patterns between LISSV and PLXNA4, we studied three types of neural-specific gene expression. As shown in Figure 10, the induction of neural differentiation by LISSV was non-specific, but only the MAP2 and NEUROD1 genes were expressed by the PLXNA4 
recombinant protein. Differentiation of hUC-MSCs by the PLXNA4 recombinant protein is thought to be induced specifically in neurons.

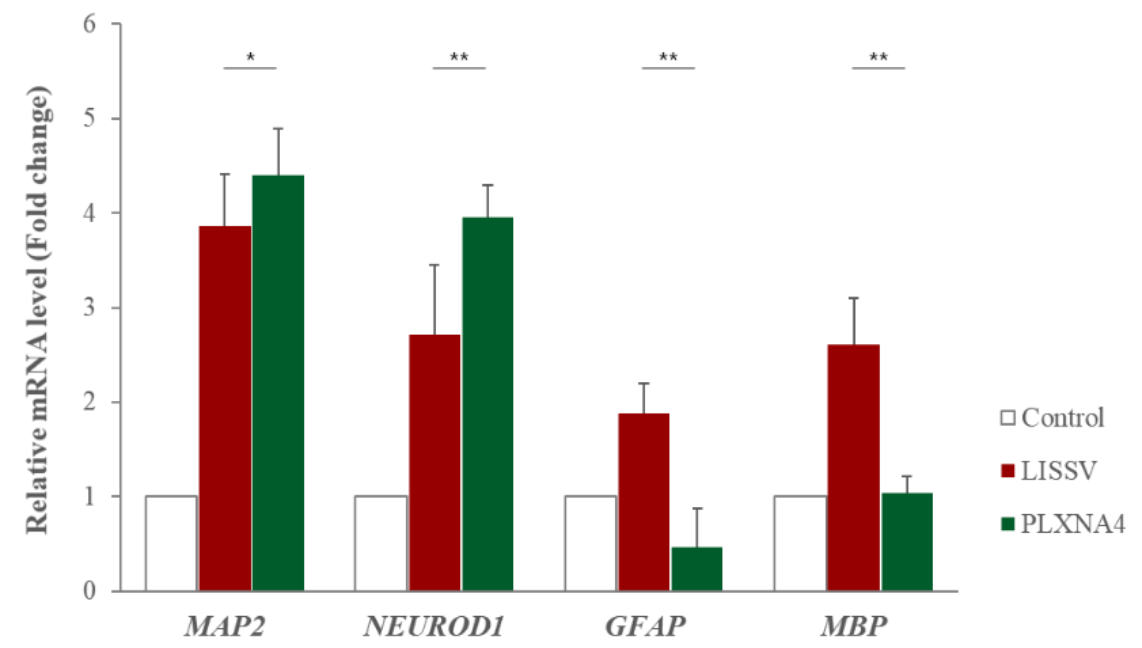

Figure 10. Expression of neural differentiation-specific genes in human umbilical-cord-derived mesenchymal stem cells after low-intensity sub-sonic vibration versus recombinant PLXNA4 protein. Cells were harvested 4 days after low-intensity sub-sonic vibration treatment and 5 days after recombinant PLXNA4 protein treatment. The fold change in the expression of each gene was analyzed using a real-time polymerase chain reaction. MAP2: Microtubule-associated protein 2. NEUROD1: Neuronal Differentiation 1, GFAP: Glial Fibrillary Acidic Protein, MBP: Myelin basic protein. Column heights correspond to mean values and error bars to standard deviations $(n=3)$. ${ }^{*} p<0.05,{ }^{* *} p<0.01$.

We thought that MSC-specific markers were no longer expressed when differentiation was induced by both LISSV and recombinant PLXNA4 protein. CD73, CD105, and CD90 are markers specifically expressed in human MSCs [29]. In Fluorescence-activated cell sorting (FACS) analysis, we analyzed anti-CD73 and anti-CD105 expression after LISSV and recombinant PLXNA4 protein treatment (Figure 11). Before treatment, anti-CD73 was expressed at $97.8 \%$ in hUC-MSCs and anti-CD105 was expressed at $81.3 \%$. Before treatment, anti-CD73 was expressed at $97.8 \%$ and anti-CD105 was expressed at $81.3 \%$ in hUC-MSCs. When LISSV was given for 3 days, the expression of anti-CD73 was reduced to $90.4 \%$, and anti-CD105 was reduced to $62.5 \%$. In the case of PLXNA4 treatment, the expression of antiCD73 was reduced to $83.2 \%$, like LISSV, and anti-CD105 was also reduced to $62.5 \%$. Both LISSV and recombinant PLXNA4 protein treatment reduced the expression of MSC-specific markers, suggesting that the differentiation process of hUC-MSCs is in progress.

Plexins are proteins involved in the signaling of the semaphorin family, and plxna4 belongs to class A of four types. Class A plexins interact with neuropilin co-receptor proteins, and specifically, the plxna4 and neuropilin signaling cascade can be activated by both SEMA3A and SEMA6A [30]. To identify semaphorins involved in inducing the expression of neuron-associated proteins in hUC-MSCs, we analyzed the expression of both SEMA3A and SEMA6A. SEMA3A was increased selectively (Figure 12) and its downstream signaling molecule, FYN, was activated in a time-dependent manner (Figure 13). Presynaptic vesicles for neurite outgrowth in neurons are induced through the activation of this signal. GAP43 regulates presynaptic vesicle interactions and SYN1 and synaptophysin proteins are presynaptic vesicle proteins. LISSV and the recombinant PLXNA4 protein increased the expression levels of SYN1, GAP43, and synaptophysin genes (Figure 14). The expression of neuron-related proteins was induced by activation of the semaphorin 3A-dependent plexin-A4 signaling cascade by LISSV in hUC-MSCs. 


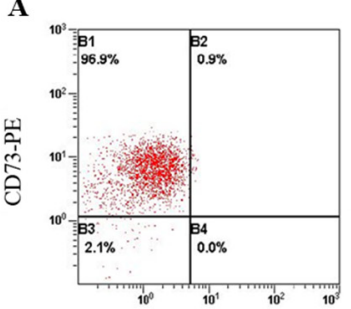

D

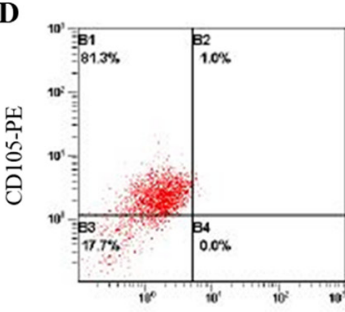

B

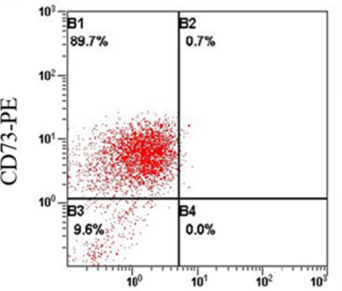

E

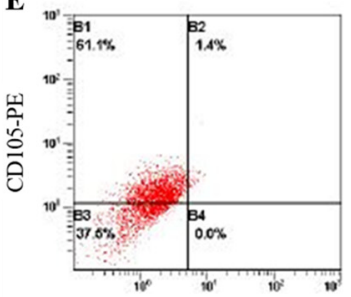

C
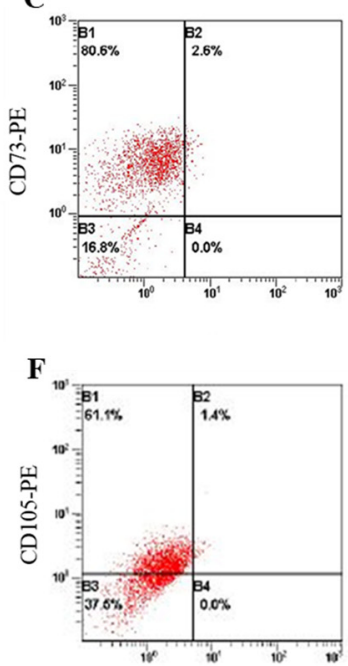

Figure 11. The changes of specific markers in human umbilical-cord-derived mesenchymal stem cells by low-intensity sub-sonic vibration and recombinant PLXNA4 protein treatment using FACS analysis. Cells were harvested 3 days after each treatment. PE-conjugated anti-CD73 and PEconjugated anti-CD105 were used. (A,D) Control. (B,E) LISSV treatment. (C,F) $2 \mu \mathrm{g} / \mathrm{mL}$ recombinant PLXNA4 protein treatment.

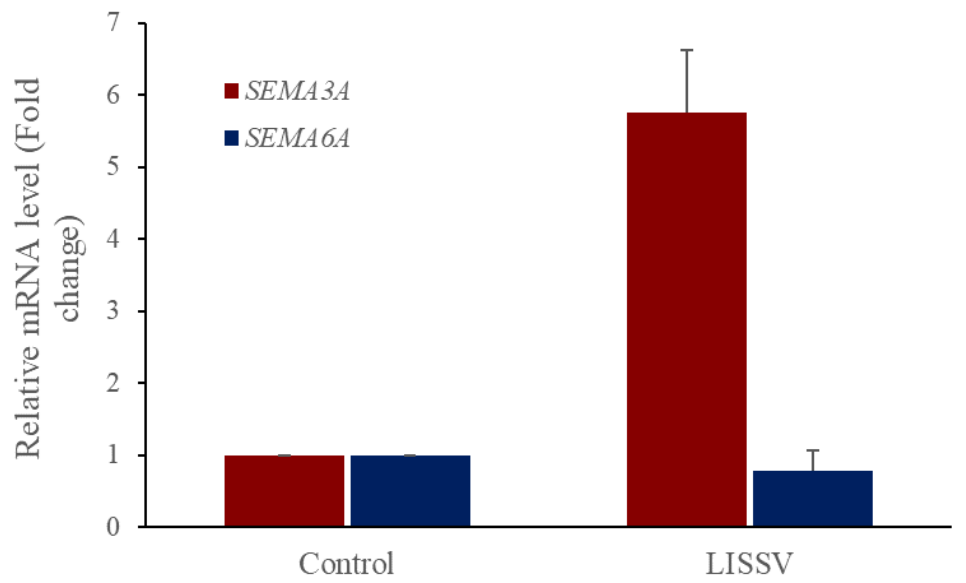

Figure 12. Expression of PLXNA4-dependent semaphorin signaling molecules in human umbilicalcord-derived mesenchymal stem cells by low-intensity sub-sonic vibration using real-time polymerase chain reaction analysis. Cells were harvested 4 days after low-intensity sub-sonic vibration treatment. SEMA3A: Semaphorin 3A, SEMA6A: Semaphorin 6A. Column heights correspond to mean values and error bars to standard deviations $(n=3)$.

$$
\text { Cont } \quad 3 \mathrm{D} \quad 4 \mathrm{D} \quad 5 \mathrm{D} \text { (Day) }
$$

FYN

\section{$\beta$-actin}

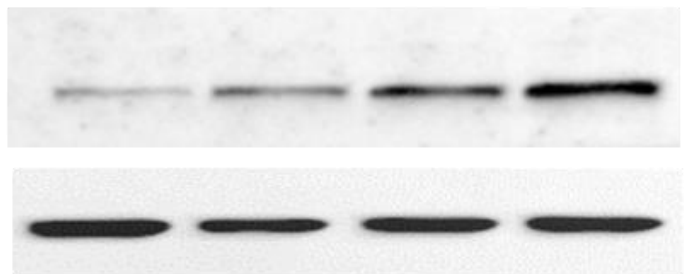

Figure 13. Expression of PLXNA4-dependent semaphorin signaling protein in human umbilical-cordderived mesenchymal stem cells by low-intensity sub-sonic vibration. FYN: Src Family of nonreceptor tyrosine kinase $p 59$. 


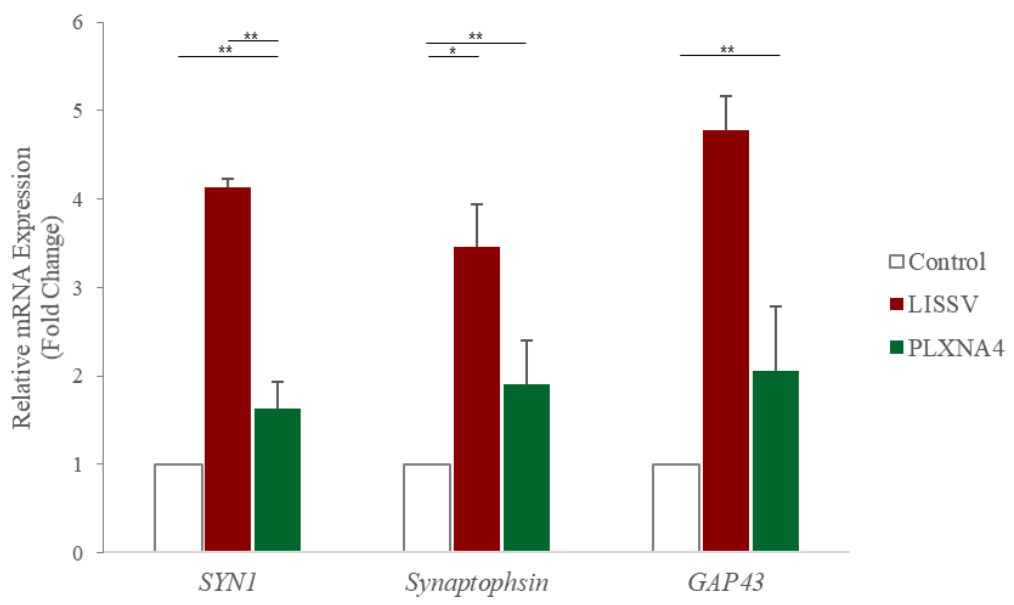

Figure 14. Expression of presynaptic vesicle protein-associated genes in human umbilical-cordderived mesenchymal stem cells after low-intensity sub-sonic vibration versus recombinant PLXNA4 protein. Cells were harvested 4 days after low-intensity sub-sonic vibration treatment and 5 days after recombinant PLXNA4 protein treatment. The fold change in the expression of each gene was analyzed using real-time polymerase chain reaction. SYN1: Synapsin 1, GAP43: Growth-Associated Protein 43 , Column heights correspond to mean values and error bars to standard deviations $(n=3)$. ${ }^{*} p<0.05,{ }^{* *} p<0.01$.

\section{Discussion}

In a previous study, we reported the neural differentiation of hUC-MSCs by LISSV. These changes are specifically due to mechanical stimulation in cells that were lacking growth factors and cytokines for the differentiation process. To find genes involved in this differentiation, RNA sequencing analysis was performed after LISSV exposure in hUC-MSCs.

RNA sequencing is a very useful technique for elucidating the presence and sequences of RNA in a sample using next-generation sequencing. This technique shows changes in the cellular transcriptome at a given moment. After 4 days of exposure to LISSV, the hUC-MSCs changed their shape to a neuron-like morphology, at which time the cells were harvested for RNA sequencing. First, we focused on upregulated genes, and among 16 genes, 5 genes were identified using real-time PCR: PLXNA4, FMN1, AREG, STMN2, and SERPINI1. Among these, four genes were expressed at the protein level in a time-dependent manner. PLXNA4 increased gradually over 6 days, and FMN1 decreased. The PLXNA4 gene belongs to the plexin A family, and plexin A is a neuronal semaphorin receptor involved in axon guidance during neural development and neuron migration to synaptic organization [31-34]. In neurons, semaphorins transduce activation signals through plexin receptor proteins and the neuropilin family [35]. The recombinant PLXNA4 protein was used to study the role of the PLXNA4 gene in hUC-MSC differentiation by LISSV. The PLXNA4 gene was well expressed when $1.5 \mathrm{~g}$ or $2.0 \mathrm{~g}$ per well was added to hUC-MSCs. Cell proliferation was inhibited without dead cells. Thus, the reduction of cells by the PLXNA4 protein in the MTT assay indicates that hUC-MSCs have entered the differentiation process. After 5 days, a morphological change was induced and the morphology was close to that of a neuron. The cell body shone brightly, and two filaments extended in both directions around the cell body. Neuronal differentiation-related proteins such as MAP2, NEUROD1, and NF-L were expressed strongly in the immunofluorescence analysis, and the same results were confirmed in real-time PCR assays. These proteins and genes were also expressed in hUC-MSCs by LISSV [21], and the morphology of the differentiated cells was very similar in both cases. We observed that the differentiation process of hUC-MSCs induced by LISSV and PLXNA4 was slightly different. In our previous report, when LISSV was given to hUC-MSCs, differentiation of hUC-MSCs was a neural non-specific process, so all three types of neural cell markers, astrocytes, oligodendrocytes, and neurons, were 
induced. However, PLXNA4-induced differentiation in hUC-MSCs is a neuron-specific process, as GFAP and MBP were not expressed. Voltage-gated calcium channels are the main mediators that allow calcium to flow into neurons when depolarization occurs. The Cav2.1 is a P/Q-type calcium channel, and Cav2.2 is an N-type calcium channel, while P/Q and $\mathrm{N}$ channels trigger neurotransmitter release [36]. The recombinant PLXNA4 protein induced neural differentiation while expressing Cav2.1 and Cav2.2.

hUC-MSCs are cells capable of self-renewal and differentiation into various lineages [37]. Wharton's jelly derived from the human umbilical cord contains a higher amount of primitive MSCs compared to MSCs derived from bone marrow [38]. When MSCs begin to differentiate into cells of other lineages, those cells cannot maintain their stemness. Human MSCs express CD73, CD90, and CD105, but not CD34, CD45, or CD14 [39,40]. During both LISSV and recombinant PLXNA4 protein treatment, the expression of hUC-MSC specific markers, CD73 and CD105, was reduced. Therefore, those cells have begun to differentiate into other cells, particularly nerve-like cells.

To validate the function of the PLXNA4 gene, PLXNA4 gene silencing using siRNA analysis was performed. This assay was transient, and only 20-27 base pairs were used for gene silencing. After transfection of a specific gene base pair for an interfering RNA, the expression of the specific gene interferes with the complementary nucleotide sequence so the mRNA is degraded after transcription. In this assay, we used a transfection reagent for siRNA duplex transfection. The viable cells reached over $90 \%$ after transfection. We observed morphological changes and PLXNA4 gene silencing in hUC-MSCs. After silencing, no change was noted in the level of PLXNA4 gene expression in both the silencing Negative (siNegative) and PLXNA4 (siPLXNA4) without LISSV. However, in the case of LISSV exposure, PLXNA4 gene expression increased only in the silencing Negative (siNegative) expression group, and no change took place in the silencing PLXNA4 (siPLXNA4) expression group. The same results were observed in the morphological change data, and in the case of silencing PLXNA4 (siPLXNA4) expression, no morphological change occurred after exposure to LISSV. To confirm the neuronal differentiation after silencing PLXNA4 (siPLXNA4) expression in hUC-MSCs, we analyzed the neuron-related gene expression by LISSV. After silencing PLXNA4 (siPLXNA4) expression, the expression of neuron-related genes, NF- L, MBP, and $M A P 2$, was unchanged compared to the controls and silencing Negative (siNegative) without LISSV groups. Consequently, we established that the PLXNA4 gene is associated with the neural differentiation of hUC-MSCs by LISSV.

The interaction of the neuropilin (Nrp)/plexin receptor complex and semaphorins plays an important role in axonal development in the central nervous system. This complex is also involved in a variety of other developmental processes, spanning from cell polarization to migration to neuronal maturation [41]. The semaphorin protein family consists of eight classes and is found in vertebrates and invertebrates. Plexin receptors for SEMA are classified into four classes, and plexin-A4 interacts with specific SEMA classes to mediate signal activation. The Nrp/PLXNA4 receptor complex interacts with class 3 and class 6 semaphorins and is involved in axon guidance and anti-angiogenesis when interacting with class 3 semaphorins [42,43]. SEMA3A, one of the class 3 semaphorins, interacts with plexins-A1 and -A4 to induce cytoskeletal disruption, the inhibition of cell proliferation, and adhesion in endothelial cells [44]. SEMA6A acts as a chemical repellent for sympathetic axons and is involved in lamina-specific axon formation in the hippocampus $[45,46]$. To identify SEMAs interacting with PLXNA4 in hUC-MSCs by LISSV, we analyzed the gene expression of $S E M A 3 A$ and $S E M A 6 A$ after LISSV exposure. We found that $S E M A 3 A$ is upregulated by 5 -fold, but the level of $S E M A 6 A$ is not changed. When the $\mathrm{Nrp} /$ plxna4 receptor complex interacted with $S E M A 3 A$, its downstream molecule, FYN, is recruited for signal activation, which is involved in the process of collapse for cell differentiation [47]. We confirmed that the FYN protein increases in a time-dependent manner. These results showed that increased levels of PLXNA4 expression induced by LISSV in hUC-MSCs are associated with an increase in SEMA3A, and that neuronal differentiation of 
hUC-MSCs induced by LISSV is thought to be due to semaphorin 3A-plexin-A4-dependent signaling activation.

Sema3A regulates the density of the dendritic spine, small membrane protrusions from dendrites of neurons [48,49], and this signaling activation induces growth cone collapse and neuronal cells $[41,50]$. SYN1 and Synaptophysin are presynaptic vesicle proteins located in the cytoplasmic membrane of the presynapse, and GAP43, a neuromodulin, plays a role in regulating presynaptic vesicular function and axonal growth [51,52]. The expression of SYN1, GAP43, and synaptophysin was induced in hUC-MSCs through sema3 signaling activation upon treatment with LISSV and the recombinant PLXNA4 protein.

Many studies have reported the differentiation of MSCs, which is multi-day dependent and requires various growth and neurotropic factors and cytokines [53-55]. We reported neuronal differentiation of hUC-MSCs caused by LISSV alone, a mechanical stimulus. After 4-5 days, the shape of hUC-MSCs modified to neuron-like and neuron-related genes were expressed. This neuronal differentiation was activated through the Nrp/plxna4 receptor complex with the SEMA3A-dependent signaling mechanism. Discovering the specific mechanism that induces neural differentiation in hUC-MSCs via LISSV and applying it to neurodegenerative disorders will be very useful in stem cell therapy.

\section{Materials and Methods}

\subsection{Cell Culture}

hUC-MSCs were purchased from the American Type Culture Collection (ATCC, Washington, D.C., VA, USA) and were cultured in a nonhematopoietic (NH) stem cell medium (Miltenyi Biotech, Bergisch Gladbach, Germany) supplemented with 100 units/mL of penicillin and $100 \mu \mathrm{g} / \mathrm{mL}$ of streptomycin (Invitrogen, Carlsbad, CA, USA). Passage 6-10 cells were used in this experiment and the culture medium was replaced every 3-4 days. When hUC-MSCs reached approximately $80 \%$ density in $100 \mathrm{~mm}$ culture dishes, they were passaged in a 1:4 plate ratio using accutase (Innovative Cell Tech., San Diego, CA, USA) for cell isolation. One day before the experiment, the medium was replaced with low-glucose DMEM (LDMEM) supplemented with 10\% FBS (Invitrogen, Carlsbad, CA, USA) followed by LISSV exposure.

\subsection{LISSV Exposure}

A Turbosonic Low-Intensity Sub-Sonic Vibrator (Turbosonic Korea, Seoul, Korea) was used [8]. The machine moves up and down creating undulating waves in the medium, which affects the cells. The hUC-MSCs were cultured at a low density and exposed to LISSV continuously for 4 days at a frequency of $30 \mathrm{~Hz}$ and acceleration of 13.5 to 14.1 after 1 day.

\subsection{Cell Growth Assay}

A cell growth assay was performed using 3-(4,5-dimethylthiazol-2-yl)-2,5-diphenyltetrazolium bromide (MTT) (Sigma-Aldrich, St. Louis, MO, USA) solution as an indicator of cell viability and proliferation. Viable cells containing $\mathrm{NAD}(\mathrm{P}) \mathrm{H}$-dependent oxidoreductase enzymes were reduced to formazan by MTT. The MTT solution is added to cells in culture, at a final concentration of $0.83 \mathrm{mg} / \mathrm{mL}$, and incubated for $3.5 \mathrm{~h}$. At $570 \mathrm{~nm}$, the absorbance was measured using a Versamax microplate reader (Molecular Device, Sunnyvale, CA, USA).

\subsection{RNA-Sequencing Assay}

The total RNA was extracted from the samples as above, and the concentration and purity were determined using a spectrophotometer with optical densities of A260 and A260/A280. RNA sequencing libraries of each sample were prepared using the TruSeq RNA Library Prep Kit (Illumina, San Diego, CA, USA), and the result was obtained using the Illumina HiSeq 2000 system. RNA-seq experiments were performed on hUC-MSCs exposed to LISSV for 4 days. The levels of gene expression were normalized to RPKM/FPKM (reads of paired-end fragments per kb of exon model per million mapped reads/fragment 
per $\mathrm{kb}$ of transcript per million mapped reads). The quality of the sequencing reads obtained from RNA-sequencing experiments was validated using an Excel-based differentially expressed gene analysis tool. Heatmaps were generated to visualize transcriptome differences between the control and LISSV.

\subsection{Treatment with Recombinant PLXN4 Protein}

The purified recombinant protein of human Plexin-A4 was purchased from OriGene Technologies Inc. (Rockville, MD, USA). The hUC-MSCs were cultured with a density of $1 \times 10^{5}$ cells $/ 35 \mathrm{~mm}$ dish, and the PLXNA4 recombinant protein 1.5 and $2.0 \mu \mathrm{g} / 100 \mu \mathrm{L}$ medium was added 1 day later. The morphological changes in the cells were observed every day. After 5 days, cell images were obtained using an optical microscope.

\subsection{Small Interfering $R N A$ (siRNA) Transfection}

For gene silencing, the siTran 2.0 transfection reagent from OriGene Technologies Inc. (Rockville, MD, USA) was used. In total, $8 \times 10^{3}$ cells were seeded before transfection in 6-well culture plates, and $1 \mathrm{~mL}$ of growth media, $90 \mathrm{nmol}$ siPLXNA4 Oligo duplex, $2.4 \mu \mathrm{L}$ of the siTran 2.0 transfection reagent, and $100 \mu \mathrm{L}$ of the transfection buffer were added to the cells. To lower the cytotoxicity, the medium was replaced $24 \mathrm{~h}$ after the addition of the transfection complex, and the cells were harvested $24 \mathrm{~h}$ later. The sequences of the siRNAs were as follows: siPLXNA4, 5'-CGCAUAUGUCUACAAGAACCACUCT-3'; and siNegative control, 5' - CGUUAAUCGCGUAUAAUACGCGUAT-3'.

\subsection{Polymerase Chain Reaction (PCR) and Real-Time qPCR}

Total RNA extraction from hUC-MSCs was performed using the Trizol solution (Qiagen, Valencia, CA, USA) and cDNA was obtained from total RNA using an Advantage RTPCR kit (Clontech, Palo Alto, CA, USA). Table 1 shows the primer sequences used for realtime qPCR. The following genes were examined: Plexin A4 (PLXNA4), Formin 1 (FMN1), Amphiregulin (AREG), Stathmin 2 (STMN2), Serpin Family I Member 1 (SERPINI1), Microtubule-associated protein 2 (MAP2), Neuronal Differentiation 1 (NEUROD1), Glial fibrillary acidic protein $(G F A P)$, Myelin basic protein $(M B P)$, and Neurofilament-L (NF- $L)$.

Table 1. Primer sequences used for RT-PCR.

\begin{tabular}{|c|c|c|}
\hline Genes & Upstream Primer Sequence & Downstream Primer Sequence \\
\hline PLXNA4 & $5^{\prime}$-ATC TCC GTC TCT CAG TAC AA-3' & 5'-GTG ATA GGC TTG ATC ACC TC-3' \\
\hline FMN1 & 5'-CCA TCA CCG TTT ТCT ТCT ТC-3' & 5'-AGT TAC AGT GCC CTT GTA TG-3' \\
\hline AREG & $5^{\prime}$-TTC TAG TAG TGA ACC GTC CT-3' & 5'-AGA CAT AAA GGC AGC TAT GG-3' \\
\hline STMN2 & $5^{\prime}$-CAG AGG GAA GGA GAG AAG CAA T-3' & 5'-TCA TTA GGC AAT GGT GGG TT-3' \\
\hline SERPINI1 & $5^{\prime}$-AAA ACC TCT CGG GTG AAA G-3' & $5^{\prime}$-GCT GTC ATA TCC CAT TGA GT-3' \\
\hline MAP2 & $5^{\prime}$-СTC AAC AGT TCT ATC TCT TCT TCA-3' & $5^{\prime}$-TCT TCT TGT TTA AAA TCC TAA CCT- $3^{\prime}$ \\
\hline NFL & 5'-CAA GAA CAT GCA GAA CGC TG-3' & 5'-GCC TTC CAA GAG TTT CCT GT-3' \\
\hline NEUROD1 & 5'-ACA GTC ACC AGT GTG GTG GA-3' & $5^{\prime}$-CGT AGC CTC TGG AGA ACC TG-3' \\
\hline GFAP & 5'-TCATCGCTCAGGAGGTCCTT-3' & 5'-CTGTTGCCAGAGATGGAGGTT-3' \\
\hline$M B P$ & $5^{\prime}$-CGG CAA CTA CGT GCT CTT CA-3' & $5^{\prime}$-GTG ACT TCA TCT CGT GGG CC-3' \\
\hline SEMA3A & $5^{\prime}$-TAA GGA GAA AGG AGG AGA GGT G-3' & 5'-GTG CTG GTT TGA ACT AGA GG-3' \\
\hline$S E M A 6 A$ & $5^{\prime}$-TTA CAA CAC AGT GTA TGG GC-3' & $5^{\prime}$-CTT TGA GGT AAC TTT CCC GA-3' \\
\hline SYN1 & 5'-GCT CAA CAA ATC CCA GTC TC-3' & 5'-GAG GAG TCA GGT TTC TCA AG-3' \\
\hline Synaptophysin & 5'-CCT ATA CCC TAG GTC TCC AC-3' & 5'-CCT GTC CTC CTT TTA GAT CC-3' \\
\hline GAP43 & 5'-CCA TGC TGT GCT GTA TGA GAA G-3' & 5'-TAA GGA CTA GGT CGA ACT GC-3' \\
\hline Cav2.1 & $5^{\prime}$-CCG TGT GAT AAG AAC TCT GG-3' & $5^{\prime}$-GAC ATG TGT CTC AGC ATC-3' \\
\hline Cav2.2 & $5^{\prime}$-CCA TCT TCT ACG TGG TCT AC-3' & 5'-CAT CAG CTC GTA CTC ATA GG-3' \\
\hline GAPDH & $5^{\prime}$-ACC ACA GTC CAT GCC ATC AC-3' & $5^{\prime}$-TCC ACC ACC CTG TTG CTG TA-3' \\
\hline
\end{tabular}

Real-time qPCR was performed according to the SimpliAmp Thermal Cycler (Applied Biosystems, Foster City, CA, USA), which enables real-time quantitative detection of PCR products based on SYBR green fluorescence due to the incorporation of SYBR 
green into double-stranded DNA. The results were analyzed by a comparative cycle threshold (CT) method for the quantification of relative gene expression for the housekeeping gene $(G A P D H)$.

\subsection{Western Blot Analysis}

Cells were washed with phosphate-buffered saline (PBS) and scraped in radioimmunoprecipitation assay (RIPA) buffer (Abcam, Cambridge, UK) containing protease and a phosphatase inhibitor cocktail (Abcam, Cambridge, UK). Protein concentrations of total lysates were determined using the bicinchoninic acid (BCA) protein assay (Pierce Biotechnology, Rockford, IL, USA). For Western blot analysis, $1 \mu \mathrm{g} / \mu \mathrm{L}$ of proteins was loaded on $10 \%$ polyacrylamide gels, and the blots were transferred to nitrocellulose membranes. To prevent non-specific binding of the antibody to the membranes, the nitrocellulose membranes were shaken with 5\% skim milk in Tris-acetate-EDTA (TAE) buffer for $30 \mathrm{~min}$, followed by incubation with 1st antibodies such as anti-SERPINI1 (Santa Cruz Biotechnology Inc., Dallas, TX, USA), anti-PLXNA4 (R\&D systems, Minneapolis, MN, USA), anti-FMN1 (Abcam, Cambridge, UK), anti-AREG (Abcam, Cambridge, UK), anti-FYN (Cell Signaling Technology, Boston, MA, USA), and $\beta$-actin (Sigma, St. Louis, MO, USA) at the appropriate dilutions overnight at $4{ }^{\circ} \mathrm{C}$. The 1st antibody was diluted using the TAE buffer with $5 \%$ bovine serum albumin (Sigma-Aldrich, St. Louis, MO, USA). After three washes, membranes were incubated with anti-mouse and anti-rabbit secondary antibodies in 5\% skim milk in the TAE buffer, then exposed to the SuperSignal West Femto Maximum Sensitivity Substrate (Thermo Scientific, Rockford, IL, USA) and autoradiographically imaged using the ChemiDoc XRS+ System (Bio-Rad, Hercules, CA, USA).

\subsection{Immunofluorescence Imaging}

In total, $5 \times 10^{3}$ hUC-MSCs were cultured in 12-well plates, and the recombinant PLXNA4 protein was added 1 day later. After 5 days, cells were fixed with $4 \%$ paraformaldehyde solution for $10 \mathrm{~min}$. Cells were shaken with a blocking solution (TAE buffer containing $1.5 \%$ bovine serum albumin) supplemented with $0.5 \%$ Triton X-100 for cell permeability, then incubated with the primary antibody overnight at $4{ }^{\circ} \mathrm{C}$, including the anti-MAP2, anti-NEUROD1, anti-MBP, anti-MBP antibodies (Cell Signaling Technology, Boston, MA, USA).After washing, the cells were incubated with human secondary antibodies conjugated with the Alexa Fluor 488 conjugate and Alexa Fluor 555 conjugate (Cell Signaling Technology, Boston, MA, USA) for $1 \mathrm{~h}$ at room temperature. Glass coverslips were then counterstained with the Vectashield Antifade mounting medium (Vector Laboratories, Burlingame, CA, USA) and mounted onto microscope slides. Cells were examined using a Ts2R-FL microscope (Nikon, Tokyo, Japan).

\subsection{Fluorescence-Activated Cell Sorting (FACS) Analysis}

Both PE-conjugated anti-CD73 and PE-conjugated anti-CD105 antibodies were purchased from Abcam (Cambridge, UK). A total of $1 \times 10^{5}$ cells were re-suspended in $500 \mu \mathrm{L}$ ice-cold PBS with 3\% bovine serum albumin (Sigma-Aldrich, St. Louis, MO, USA) and incubated with antibodies for overnight at $4{ }^{\circ} \mathrm{C}$. After washing, flow cytometry was performed using the NovoCyte Flow Cytometer (Agilent Technologies, Santa Clara, CA, USA), and the data were analyzed using Novoexpress software (Agilent Technologies, Santa Clara, CA, USA).

\subsection{Statistical Analysis}

Data are shown as the mean \pm SD of three independent experiments. An analysis of variance followed by Tukey's multiple comparisons test was performed using GraphPad Prism (La Jolla, CA, USA). Mean differences are shown to be significant at ${ }^{*} p<0.05$, and ** $p<0.01$. 


\begin{abstract}
Author Contributions: Conceptualization, H.C. and Y.-K.S.; methodology, H.C. and H.-J.P.; software, H.C.; validation, H.C.; formal analysis, H.C. and H.-J.P.; investigation, H.C.; resources, H.C.; data curation, H.C.; writing-original draft preparation, H.C.; writing—review and editing, Y.-K.S.; visualization, H.C., H.-J.P.; supervision, Y.-K.S.; project administration, H.C.; funding acquisition, H.C. All authors have read and agreed to the published version of the manuscript.
\end{abstract}

Funding: This research was supported by the Basic Science Research Program through the National Research Foundation of Korea (NRF) funded by the Ministry of Education (NRF-2019R1A2C1006321).

Institutional Review Board Statement: Not applicable.

Informed Consent Statement: Not applicable.

Data Availability Statement: Data available upon reasonable request.

Conflicts of Interest: The authors declare no conflict of interest.

\title{
References
}

1. Huang, Y.; Jia, X.; Bai, K.; Gong, X.; Fan, Y. Effect of Fluid Shear Stress on Cardiomyogenic Differentiation of Rat Bone Marrow Mesenchymal Stem Cells. Arch. Med. Res. 2010, 41, 497-505. [CrossRef] [PubMed]

2. Maul, T.M.; Chew, D.W.; Nieponice, A.; Vorp, D.A. Mechanical stimuli differentially control stem cell behavior: Morphology, proliferation, and differentiation. Biomech. Model. Mechanobiol. 2011, 10, 939-953. [CrossRef]

3. Kim, D.H.; Heo, S.J.; Kim, S.H.; Shin, J.W.; Park, S.H.; Shin, J.W. Shear stress magnitude is critical in regulating the differentiation of mesenchymal stem cells even with endothelial growth medium. Biotechnol. Lett. 2011, 33, 2351-2359. [CrossRef] [PubMed]

4. Dan, P.; Velot, É.; Decot, V.; Menu, P. The role of mechanical stimuli in the vascular differentiation of mesenchymal stem cells. J. Cell Sci. 2015, 128, 2415-2422. [CrossRef]

5. Fahy, N.; Alini, M.; Stoddart, M.J. Mechanical stimulation of mesenchymal stem cells: Implications for cartilage tissue engineering. J. Orthop. Res. 2018, 36, 52-63. [CrossRef]

6. $\quad$ Lin, S.; Lee, W.Y.W.; Feng, Q.; Xu, L.; Wang, B.; Man, G.C.W.; Chen, Y.; Jiang, X.; Bian, L.; Cui, L.; et al. Synergistic effects on mesenchymal stem cell-based cartilage regeneration by chondrogenic preconditioning and mechanical stimulation. Stem. Cell. Res. Ther. 2017, 8, 221. [CrossRef] [PubMed]

7. Wang, J.; Wang, C.D.; Zhang, N.; Tong, W.X.; Zhang, Y.F.; Shan, S.Z.; Zhang, X.L.; Li, Q.F. Mechanical stimulation orchestrates the osteogenic differentiation of human bone marrow stromal cells by regulating HDAC1. Cell Death Dis. 2016, 7, e2221. [CrossRef]

8. $\quad$ Pagnotti, G.M.; Styner, M.; Uzer, G.; Patel, V.S.; Wright, L.E.; Ness, K.K.; Guise, T.A.; Rubin, J.; Rubin, C.T. Combating osteoporosis and obesity with exercise: Leveraging cell mechanosensitivity. Nat. Rev. Endocrinol. 2019, 15, 339-355. [CrossRef]

9. Rubin, C.; Turner, A.S.; Bain, S.; Mallinckrodt, C.; McLeod, K. Anabolism. Low mechanical signals strengthen long bones. Nature 2001, 412, 603-604. [CrossRef]

10. Rubin, C.; Turner, A.S.; Müller, R.; Mittra, E.; McLeod, K.; Lin, W.; Qin, Y.X. Quantity and quality of trabecular bone in the femur are enhanced by a strongly anabolic, noninvasive mechanical intervention. J. Bone Min. Res. 2002, 17, 349-357. [CrossRef]

11. Pagnotti, G.M.; Kurihara, N.; Roodman, G.D. Low Intensity Vibration Treatment Reduces Myeloma Cell-Induced Osteoclast Formation By Inhibiting IL-6 and GFI-1 Production By MM Cells. Blood 2017, 130, 1775.

12. Pongkitwitoona, S.; Weinheimer-Hausb, E.M.; Koh, T.J.; Judex, S. Low-intensity vibrations accelerate proliferation and alter macrophage phenotype in vitro. J. Biomech. 2016, 49, 793-796. [CrossRef] [PubMed]

13. Pagnotti, G.M.; Chan, M.E.; Adler, B.J.; Shroyer, K.R.; Rubin, J.; Bain, S.D.; Rubin, C.T. Low Intensity Vibration Mitigates Tumor Progression and Protect Bone Quantity and Quality in a Murine Model of Myeloma. Bone 2016, 90, 69-79. [CrossRef] [PubMed]

14. Suto, F.; Murakami, Y.; Nakamura, F.; Goshima, Y.; Fujisawa, H. Identification and characterization of a novel mouse plexin, plexin-A4. Mech. Dev. 2003, 120, 385-396. [CrossRef]

15. Suto, F.; Ito, K.; Uemura, M.; Shimizu, M.; Shinkawa, Y.; Sanbo, M.; Shinoda, T.; Tsuboi, M.; Takashima, S.; Yagi, T.; et al. Plexin-A4 Mediates Axon-Repulsive Activities of Both Secreted and Transmembrane Semaphorins and Plays Roles in Nerve Fiber Guidance. J. Neurosci. 2005, 25, 3628-3637. [CrossRef]

16. Liu, R.; Tian, B.; Gearing, M.; Hunter, S.; Ye, K.; Mao, Z. Cdk5-mediated regulation of the PIKE-A-Akt pathway and glioblastoma cell invasion. Proc. Natl. Acad. Sci. USA 2008, 105, 7570-7575. [CrossRef]

17. Kong, Y.; Janssen, B.J.; Malinauskas, T.; Vangoor, V.R.; Coles, C.H.; Kaufmann, R.; Ni, T.; Gilbert, R.J.; Padilla-Parra, S.; Pasterkamp, R.J.; et al. Structural Basis for Plexin Activation and Regulation. Neuron 2016, 91, 548-560. [CrossRef]

18. Ahn, J.Y.; Rong, R.; Kroll, T.G.; Meir, E.G.V.; Snyder, S.H.; Ye, K. PIKE (Phosphatidylinositol 3-Kinase Enhancer)-A GTPase Stimulates Akt Activity and Mediates Cellular Invasion. J. Biol. Chem. 2004, 279, 16441-16451. [CrossRef]

19. Ahn, J.Y.; Hu, Y.; Kroll, T.G.; Allard, P.; Ye, K. PIKE-A is amplified in human cancers and prevents apoptosis by up-regulating Akt. Proc. Natl. Acad. Sci. USA 2004, 101, 6993-6998. [CrossRef]

20. Han, Q.; Sun, Y.A.; Zong, Y.; Chen, C.; Wang, H.F.; Tan, L. Alzheimer's Disease Neuroimaging Initiative Common Variants in PLXNA4 and Correlation to CSF-related Phenotypes in Alzheimer's Disease. Front. Neurosci. 2018, 12, 946. [CrossRef] 
21. Cho, H.; Seo, Y.K.; Jeon, S.; Yoon, H.H.; Choi, Y.K.; Park, J.K. Neural differentiation of umbilical cord mesenchymal stem cells by sub-sonic vibration. Life Sci. 2012, 9, 591-599. [CrossRef] [PubMed]

22. Choi, Y.K.; Cho, H.; Seo, Y.K.; Yoon, H.H.; Park, J.K. Stimulation of sub-sonic vibration promotes the differentiation of adipose tissue-derived mesenchymal stem cells into neural cells. Life Sci. 2012, 91, 329-337. [CrossRef] [PubMed]

23. Choi, Y.K.; Lee, D.H.; Seo, Y.K.; Jung, H.; Park, J.K.; Cho, H. Stimulation of neural differentiation in human bone marrow mesenchymal stem cells by extremely low-frequency electromagnetic fields incorporated with MNPs. Appl. Biochem. Biotechnol. 2014, 174, 1233-1245. [CrossRef] [PubMed]

24. Urnukhsaikhan, E.; Cho, T.; Mishig-Ochir, H.; Seo, Y.K.; Park, J.K. Pulsed lectromagnetic fields promote survival and neuronal differentiation of human BM-MSCs. Life Sci. 2016, 15, 130-138. [CrossRef] [PubMed]

25. Cho, H.; Choi, Y.K.; Lee, D.H.; Park, H.J.; Seo, Y.K.; Jung, H.; Kim, S.C.; Kim, S.M.; Park, J.K. Effects of magnetic nanoparticleincorporated human bone marrow-Derived mesenchymal stem cells exposed to pulsed electromagnetic fields on injured rat spinal cord. Biotechnol. Appl. Biochem. 2013, 60, 596-602. [CrossRef]

26. Choi, Y.K.; Urnukhsaikhan, E.; Yoon, H.H.; Seo, Y.K.; Cho, H.; Jeong, J.S.; Kim, S.C.; Park, J.K. Combined effect of pulsed electromagnetic field and sound wave on In vitro and In vivo neural differentiation of human mesenchymal stem cells. Biotechnol. Prog. 2017, 33, 201-211. [CrossRef]

27. Akiyama, H.; Fkuda, T.; Tojima, T.; Nikolaev, V.O.; Kamiguchi, H. Cyclic Nucleotide Control of Microtubule Dynamics for Axon Guidance. J. Neurosci. 2016, 36, 5636-5649. [CrossRef]

28. Wheeler, D.B.; Randall, A.; Tsien, R.W. Roles of N-type and Q-type Ca2+ channels in supporting hippocampal synaptic transmission. Science 1994, 264, 107-111. [CrossRef]

29. Pham, H.; Tonai, R.; Wu, M.; Birtolo, C.; Chen, M. CD73, CD90, CD105 and Cadherin-11 RT-PCR Screening for Mesenchymal Stem Cells from Cryopreserved Human Cord Tissue. Int. J. Stem. Cells 2018, 11, 26-38. [CrossRef]

30. Law, J.W.S.; Lee, A.Y.W. The Role of Semaphorins and Their Receptors in Gliomas. J. Signal Transd. 2012, 2012, 1-14. [CrossRef]

31. Winberg, M.L.; Noordermeer, J.N.; Tamagnone, L.; Comoglio, P.M.; Spriggs, M.K.; Tessier-Lavigne, M.; Goodman, C.S. Plexin A Is a Neuronal Semaphorin Receptor that Controls Axon Guidance. Cell 1998, 95, 903-916. [CrossRef]

32. Falk, J.; Castellani, V. Cellular Migration and Formation of Neuronal Connections, 1st ed.; Academic Press: Cambridge, MA, USA, 2013; pp. 87-108.

33. Bashaw, G.J.; Klein, R. Signaling from axon guidance receptors. Cold Spring Harb. Perspect. Biol. 2010, 2, a001941. [CrossRef] [PubMed]

34. Yogev, S.; Shen, K. Cellular and Molecular Mechanisms of Synaptic Specificity. Annu. Rev. Cell Dev. Biol. 2014, $30,417-437$. [CrossRef] [PubMed]

35. Pasterkamp, R.J. Getting neural circuits into shape with semaphorins. Nat. Rev. Neurosci. 2012, 13, 605-618. [CrossRef] [PubMed]

36. Benarroch, E.E. Neuronal voltage-gated calcium channels: Brief overview of their function and clinical implications in neurology. Neurology 2010, 74, 1310-1315. [CrossRef]

37. Malgieri, A.; Kantzari, E.; Patrizi, M.P.; Gambardella, S. Bone marrow and umbilical cord blood human mesenchymal stem cells: State of the art. Int. J. Clin. Exp. Med. 2010, 3, 248-269.

38. Baksh, D.; Yao, R.; Tuan, R.S. Comparison of Proliferative and Multilineage Differentiation Potential of Human Mesenchymal Stem Cells Derived from Umbilical Cord and Bone Marrow. Stem Cells 2007, 25, 1384-1392. [CrossRef]

39. Dominici, M.; Le Blanc, K.; Mueller, I.; Slaper-Cortenbach, I.; Marini, F.; Krause, D.; Deans, R.; Keating, A.; Prockop, D.; Horwitz, E. Minimal criteria for defining multipotent mesenchymal stromal cells. The International Society for Cellular Therapy position statement. Cytotherapy 2006, 8, 315-317. [CrossRef]

40. Maleki, M.; Ghanbarvand, F.; Behvarz, M.R.; Ejtemaei, M.; Ghadirkhomi, E. Comparison of Mesenchymal Stem Cell Markers in Multiple Human Adult Stem Cells. Int. J. Stem Cells. 2014, 7, 118-126. [CrossRef]

41. Limoni, G.; Niquille, M. Semaphorins and Plexins in central nervous system patterning: The key to it all? Curr. Opin. Neurobiol. 2021, 66, 224-232. [CrossRef]

42. Kigel, B.; Varshavsky, A.; Kessler, O.; Neufeld, G. Successful inhibition of tumor development by specific class-3 semaphorins is associated with expression of appropriate semaphorin receptors by tumor cells. PLoS ONE 2008, 3, e3287. [CrossRef] [PubMed]

43. Maione, F.; Molla, F.; Meda, C. Semaphorin 3A is an endogenous angiogenesis inhibitor that blocks tumor growth and normalizes tumor vasculature in transgenic mouse models. J. Clin. Investig. 2009, 119, 3356-3372. [CrossRef] [PubMed]

44. Kigel, B.; Rabinowicz, N.; Varshavsky, A.; Kessler, O.; Neufeld, G. Plexin-A4 promotes tumor progression and tumor angiogenesis by enhancement of VEGF and bFGF signaling. Blood 2011, 118, 4285-4296. [CrossRef] [PubMed]

45. Haklai-Topper, L.; Mlechkovich, G.; Savariego, D.; Gokhman, I.; Yaron, A. Cis interaction between Semaphorin6A and Plexin-A4 modulates the repulsive response to Sema6A. EMBO J. 2010, 29, 2635-2645. [CrossRef] [PubMed]

46. Suto, F.; Tsuboi, M.; Kamiya, H.; Mizuno, H.; Kiyama, Y.; Komai, S.; Shimizu, M.; Sanbo, M.; Yagi, T.; Hiromi, Y.; et al. Interactions between plexin-A2, plexin-A4, and semaphorin 6A control lamina-restricted projection of hippocampal mossy fibers. Neuron 2007, 53, 535-547. [CrossRef]

47. Nasarre, P.; Gemmill, R.M.; Drabkin, H.A. The emerging role of class-3 semaphorins and their neuropilin receptors in oncology. Onco. Targets Ther. 2014, 7, 1663-1687. 
48. Uchida, Y.; Ohshima, T.; Sasaki, Y.; Suzuki, H.; Yanai, S.; Yamashita, N.; Nakamura, F.; Takei, K.; Ihara, Y.; Mikoshiba, K.; et al. Semaphorin-3A signaling is mediated via sequential Cdk5 and GSK3 $\beta$ phosphorylation of CRMP2: Implication of common phosphorylating mechanism underlying axon guidance and Alzheimer's disease. Genes Cells 2005, 10, 165-179. [CrossRef]

49. Sasaki, Y.; Cheng, C.; Uchida, Y.; Nakajima, O.; Ohshima, T.; Yagi, T.; Taniguchi, M.; Nakayama, T.; Kishida, R.; Kudo, Y.; et al. Fyn and Cdk5 mediate Semaphorin-3A signaling, which is involved in regulation of dendrite orientation in cerebral cortex. Neuron 2002, 35, 907-920. [CrossRef]

50. Holahan, M.R. A Shift from a Pivotal to Supporting Role for the Growth-Associated Protein (GAP-43) in the Coordination of Axonal Structural and Functional Plasticity. Front. Cell. Neurosci. 2017, 11, 266. [CrossRef]

51. Pasterkamp, R.J.; Giger, R.J. Semaphorin Function in Neural Plasticity and Disease. Curr. Opin. Neurobiol. 2009, 19, $263-274$. [CrossRef]

52. Morita, A.; Yamashita, N.; Sasaki, Y.; Uchida, Y.; Nakajima, O.; Nakamura, F.; Yagi, T.; Taniguchi, M.; Usui, H.; Katoh-Semba, R. Regulation of dendritic branching and spine maturation by semaphorin3AFyn signaling. J. Neurosci. 2006, 26, 2971-2980. [CrossRef] [PubMed]

53. Kruminis-Kaszkiel, E.; Osowski, A.; Bejer-Ole'nska, E.; Dzieko'nski, M.; Wojtkiewicz, J. Differentiation of Human Mesenchymal Stem Cells from Wharton's Jelly Towards Neural Stem Cells Using a Feasible and Repeatable Protocol. Cells 2020, 9, 739. [CrossRef] [PubMed]

54. George, S.; Hamblin, M.R.; Abrahamse, H. Differentiation of Mesenchymal Stem Cells to Neuroglia: In the Context of Cell Signalling. Stem Cell Rev. Rep. 2019, 15, 814-826. [CrossRef] [PubMed]

55. Alizadeha, R.; Baghera, Z.; Kamravaa, S.K.; Falaha, M.; Hamidabadib, H.G.; Boroujenic, M.E.; Khodavedie, F.S.; Zare-Sadeghif, A.; Olyac, A.; Komeilig, A. Differentiation of human mesenchymal stem cells (MSC) to dopaminergic neurons: A comparison between Wharton's Jelly and olfactory mucosa as sources of MSCs. J. Chem. Neuroanat. 2019, 96, 126-133. [CrossRef] 